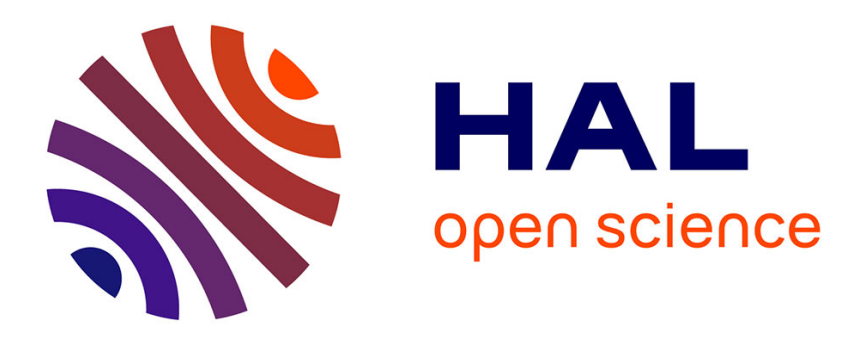

\title{
Comparison of dc and hf plasma treatments for hydrogenation of amorphous silicon
}

\author{
P.A. Thomas
}

\section{To cite this version:}

P.A. Thomas. Comparison of dc and hf plasma treatments for hydrogenation of amorphous silicon. Revue de Physique Appliquée, 1980, 15 (2), pp.241-244. 10.1051/rphysap:01980001502024100 . jpa00244721

\section{HAL Id: jpa-00244721 https://hal.science/jpa-00244721}

Submitted on 1 Jan 1980

HAL is a multi-disciplinary open access archive for the deposit and dissemination of scientific research documents, whether they are published or not. The documents may come from teaching and research institutions in France or abroad, or from public or private research centers.
L'archive ouverte pluridisciplinaire HAL, est destinée au dépôt et à la diffusion de documents scientifiques de niveau recherche, publiés ou non, émanant des établissements d'enseignement et de recherche français ou étrangers, des laboratoires publics ou privés. 


\title{
Comparison of dc and hf plasma treatments for hydrogenation of amorphous silicon
}

\author{
P. A. Thomas \\ Laboratoire de Physique des Solides $\left({ }^{*}\right)$, Université Pierre-et-Marie-Curie, \\ Tour 13, 4 place Jussieu, 75230 Paris, Cedex 05, France \\ (Reçu le 27 juillet 1979, révisé le 24 septembre 1979, accepté le 25 septembre 1979)
}

\begin{abstract}
Résumé. - La diffusion de l'hydrogène dans le silicium amorphe évaporé produit des changements des propriétés électroniques qui rendent les films utilisables pour des applications électroniques. Cette diffusion, qui a été effectuée jusqu'à présent en utilisant un plasma hf d'hydrogène, est difficilement contrôlable et présente des limitations expérimentales. On montre ici que la diffusion de l'hydrogène dans le silicium amorphe se produit lorsqu'on utilise un plasma d'hydrogène continu, et produit les mêmes changements que ceux observés après traitement hf. La diffusion de l'hydrogène à partir d'un plasma continu est très facile à contrôler et présente plusieurs autres avantages.
\end{abstract}

\begin{abstract}
Hydrogen diffusion into evaporated amorphous silicon leads to changes of the electronic properties which makes the films a useful material for electronic devices. This diffusion which has been so far realized using a hf hydrogen plasma is hardly controlled and has experimental limitations. It is shown here that hydrogen diffusion into amorphous silicon occurs when one uses a dc hydrogen plasma and produces the same changes as observed after hf treatments. Hydrogen diffusion from a dc plasma is much easier to control than the hf one and offers several other advantages.
\end{abstract}

1. Introduction. - The structure of evaporated [1] or sputtered amorphous silicon (a-Si) does not allow all covalent bonds to be satisfied. It exists a broken bonds concentration of the order of $10^{20} \mathrm{~cm}^{-3}$ which gives rise to an electronic paramagnetic resonance signal [1-3] and it also exists a weak covalent bonds concentration of the order of $3 \times 10^{21} \mathrm{~cm}^{-3}$ [4].

These defects produce a large electronic density of states in the normally forbidden band gap which makes evaporated or sputtered a-Si worthless for electronic devices : it is a bad photoconductor and doping is weakly efficient. In contrast, a-Si obtained by silane decomposition (in which it exists a concentration of hydrogen about 10-30 at. \%) exhibits all caracteristics of intrinsic semiconductors : it can be easily doped and has photoconductive properties [5]. These differences probably come from the fact that during the fabrication of the material, hydrogen atoms form covalent bonds with silicon atoms at sites where broken bonds are present and also because $\mathrm{Si}-\mathrm{H}$ bonds are more favoured than weak $\mathrm{Si}-\mathrm{Si}$ bonds :

(*) Associé au Centre National de la Recherche Scientifique. band gap states are thus reppelled in the valence band and leave a forbidden band gap in which the electronic state concentration has become weak $\left(\sim 10^{16} \mathrm{~cm}^{-3} \mathrm{eV}^{-1}\right)$.

A material whose properties are similar to those of a-Si prepared by silane decomposition was obtained after atomic hydrogen diffusion into a-Si evaporated in ultra high vacuum (UHV) [4]. Hydrogen diffusion probably allows the formation of $\mathrm{Si}-\mathrm{H}$ bonds according to the two previous mechanisms. The hydrogen diffusion method has the advantage of giving a material with a weak hydrogen atomic concentration $(\leqslant 10 \%)$ and no $\mathrm{Si}-\mathrm{H}_{\mathrm{n}}$ bonds $(\leqslant 1 \%)$ detectable by infrared absorption, in general contrast to a-Si obtained by silane decomposition.

Previous diffusion experiments were done using an hydrogen plasma produced by a high frequency electric field. This one partially decomposes molecular hydrogen into atomic hydrogen which can be easily incorporated by a-Si. In fact the use of a hf plasma is hardly controlled and we attempted to obtain controlled and reproducible experimental conditions for hydrogen diffusion using a somewhat different method ; this was achieved with an hydrogen plasma produced by a dc discharge. 
2. Use of hf discharges. Experimental limitations. - We have experimentally observed that the parameters governing hydrogen diffusion into amorphous silicon are :

- sample temperature, intensity of the hf electric field,

- pressure and flow of hydrogen.

It exists a temperature range in which hydrogen diffusion is favorable for eliminating defects in a-Si. At lower temperature, hydrogen does not penetrate into a-Si and at higher temperature one reaches an equilibrium between hydrogen incorporation and exodiffusion which forbids a complete elimination of defects. So a good thermal control of samples is needed in order to optimize diffusion conditions. This is very difficult with hf plasmas which induce currents in thermocouples and radiate luminescent light the intensity of which is generally not stable during long periods of times : this makes infrared emissivity measurements of the sample surface difficult.

Another limitation concerns the hf electric field. Plasma which is short circuited by the presence of walls, has to be maintained close to sample surface for efficient diffusion; this imply the use of high enough intensities. In these conditions the hf plasma can produce a surface erosion of the samples which leads to an inhomogeneity of both thickness and hydrogen concentration. In the extreme cases this erosion phenomena produce a complete removal of the a-Si film. Another difficulty concerns the lack of homogeneity of hf plasmas which limits the sample size and positionning.

At last, the presence of a high hf electric field constitutes a noticeable trouble as it can modify the normal operation of apparatus. These different difficulties contribute to a bad reproducibility of diffusion experiments.

3. Use of dc discharges. - We have performed hydrogen treatments of a-Si using a plasma produced by a dc discharge. Films treated in the right temperature range exhibited properties identical to those of films treated in hf hydrogen plasma, that is, high resistivity $\left(\sim 10^{7} \Omega . \mathrm{cm}\right)$, high photoconductivity and luminescence [4]. Experimental procedures are much easier to realize and to control and are not subjected to the limitations that were described.

The system used is shown on figure 1. Hydrogen is introduced through a calibrated leak in the vacuum chamber which is pumped through a controlled valve. This system allows to vary flow and pressure of hydrogen in the vacuum chamber.

The substrate of the a-Si film is placed on a sample holder which may be different depending on the way of measuring temperature. If a thermocouple is used, the sample holder is made of a piece of insulating material in which a hole has been prepared to receive

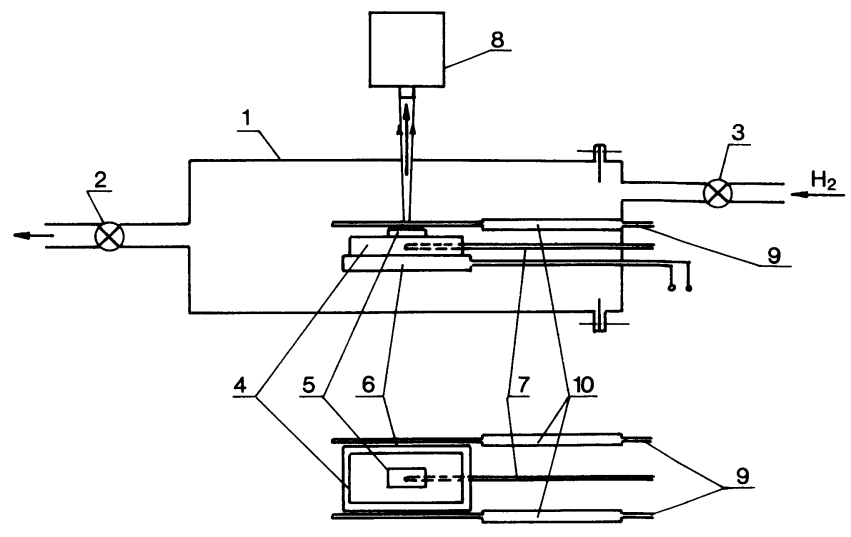

Fig. 1. - Diagram of dc hydrogenation system. 1 : Vacuum chamber. 2 : Controlled pumping valve. 3 : Calibrated leak. 4 : Sample holder. 5 : Sample substrate. 6 : Heating system. 7 : Thermocouple. 8 : Infrared radiation thermometer. 9 : Electrodes. 10 : Insulating feedthroughs.

the thermocouple. It has a good thermal contact and it is not in view of the plasma. If emissivity measurements are performed, it is better to use cristalline silicon, the infrared emissivity of which is high.

The heating of the sample holder is obtained either by an electrical resistance within the vacuum chamber or by the infrared emission of a quartz lamp located outside.

The plasma is formed between two parallel electrodes placed at both sides of the sample holder. Tungsten appears to be a good electrode material stable and unattacked by plasma. The shape and length of electrodes determine the dc plasma extension which thus can be varied easily contrary to the case of hf plasma. Maximum sample area is only limited by the increase of voltage required to make up with the increasing electrode distance. A typical current versus voltage curve is represented on figure 2 . A linear curve is obtained above a critical value $V_{0}$ and no hysteresis or instability behaviour could be observed in this regime. It allows to light off the plasma in order to control the temperature of the sample surface by emissivity measurement without any problem of reproducibility.

One can also improve the control of operating conditions by analysing the light emitted by the plasma. The relative intensity of spectral lines associated respectively with atomic and molecular hydrogen excitations characterizes accurately the plasma conditions.

Good operating conditions were obtained for temperatures of the order of $400-450^{\circ} \mathrm{C}$ and pressures in the range $0.5-10$ torr. This pressure range is larger than for hf hydrogen plasma and necessitates only primary pumping. The higher pressure also improves the thermal contact between holder and sample.

In our experiments the electrodes were $5 \mathrm{~cm}$ long and $1.3 \mathrm{~cm}$ apart. An hydrogen pressure of 1 torr, a voltage of $360 \mathrm{~V}$ corresponding to a current of 


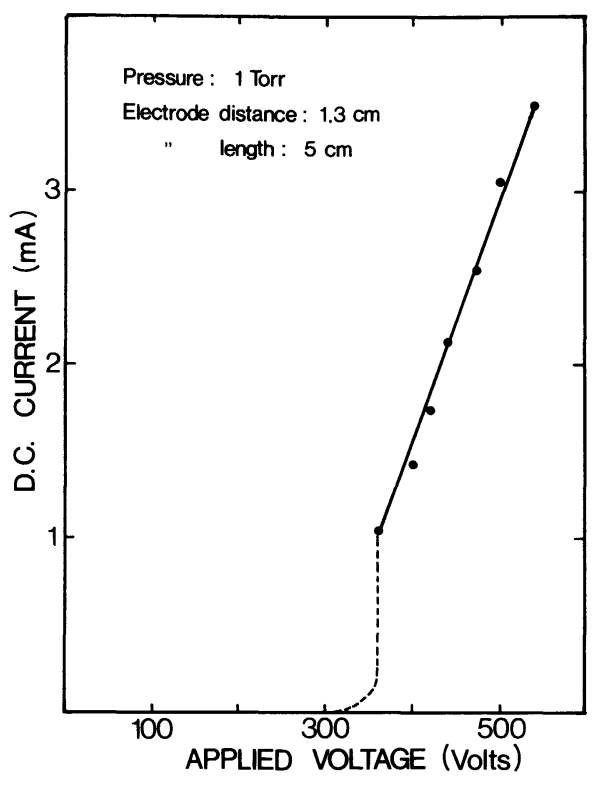

Fig. 2. - Discharge current versus applied voltage obtained at 1 torr hydrogen pressure. Above $V_{0}=360 \mathrm{~V}$ a stable and linear regime is obtained.

$1 \mathrm{~mA}$, that is a power of only $0.3 \mathrm{~W}$, were used. Under these conditions, surface attack phenomena were never observed. The plasma treatment was applied to films about $0.5 \mu \mathrm{m}$ thick during one hour and the expected electronic changes were obtained. They concern ESR signal, visible and infrared absorption, luminescence, conductivity and photoconductivity. We recall and discuss them briefly.

The ESR signal vanishes within experimental limit $\left(\leqslant 10^{17}\right.$ spins $\left.\mathrm{cm}^{-3}\right)$. This shows that each dangling electron pairs with an hydrogen atom electron. An uncomplete disappearance of the ESR signal after hydrogen treatment does indicate that diffusion is not effective throughout the whole thickness. In this case, the decrease of the ESR intensity allows to determine the hydrogen penetration depth.

The absorption coefficient in the visible decreases at all energies $\lesssim 2 \mathrm{eV}$ indicating that absorbing centers concentration (dangling and weak bonds) is strongly reduced ; it appears a gap (in the $(\alpha \mathrm{h} v)^{1 / 2} v S$ $\mathrm{h} v$ representation) of the order $1.6 \mathrm{eV}$ similar to the one of low hydrogen content silane produced films. A study of the infrared absorption coefficient allows to measure the number of hydrogen atoms which are bonded to silicon atoms in $\mathrm{Si}-\mathrm{H}$ and in $\mathrm{Si}_{-} \mathrm{H}_{\mathrm{n}}$ configurations $[6,7]$. After hydrogenation only $\mathrm{Si}-\mathrm{H}$ bonds were found [4] at a lower concentration $(\sim 3$ at. $\%$ ) than in silane produced films (10-30 at. \%). This constitutes an important advantage, as $\mathrm{Si}-\mathrm{H}_{\mathrm{n}}$ bonds do complicate the analysis and understanding of the properties of silane produced films.

On films produced from silane or sputtered in presence of hydrogen a broad $(\sim 0.3 \mathrm{eV})$ and intense luminescence peak is observed, whose maximum, at low temperatures, lies according to authors between 1.2 et $1.4 \mathrm{eV}[8,9]$. After hydrogen treatment films exhibit a luminescence spectrum at $2 \mathrm{~K}$ with similar characteristics. However the peak position is slightly shifted toward lower energies $(1.1$ to $1.2 \mathrm{eV})$ depending on preparation conditions of the deposition in UHV. Before hydrogenation, pure UHV a-Si films show a luminescence signal close to the limit of detectability, that is at least three orders of magnitude less intense than after hydrogenation [10]. A striking feature is the appearance of luminescence on unsuccessfully plasma treated films i.e., in which a decrease of the ESR intensity cannot be measured within experimental accuracy $(\leqslant 5 \%)$. This shows that a very thin hydrogenated surface layer $(\sim 100 \AA)$ gives rise to an easily detectable signal. Luminescence measurements thus appear to be complementary to ESR measurements in the case of small penetration depths.

Direct measurements of conductivity in the planar configuration show a decrease by more than two orders of magnitude after hydrogenation (from the range $10^{-3}-10^{-5}$ to $\sim 10^{-7} \Omega^{-1} \mathrm{~cm}^{-1}$ ). The temperature dependence which was close to the $\operatorname{Ln} \sigma \alpha \mathrm{T}^{-1 / 4}$ law, changes to an activated process. The very small photoconductivity of pure a-Si is also changed by orders of magnitude and reaches values similar to those of silane produced films. However one knows that on thin insulating films surface and interface states produce space charge effects which extend the whole film when Debye length compares to thickness. In this case it is not possible to determine directly the real bulk conductivity as one needs the existence of flat energy bands. These effects have been evidenced in silane produced a-Si [11-13] and can occur in our hydrogenated a-Si films thus modifying the values of conductivity and photoconductivity that were formerly given.

The determination of the hydrogen diffusion coefficient in ultra high vacuum evaporated a-Si, which is temperature dependent and which governs the minimum time of plasma treatment, is actually in progress and will be published later.

4. Conclusion. - We have shown that the diffusion of atomic hydrogen from an hydrogen plasma created by a dc electric discharge is possible into evaporated amorphous silicon films. This diffusion leads to changes of electronic properties of amorphous silicon identical to those observed when one uses a hf plasma. The main advantages of the use of a dc plasma come from the facts that operating conditions are easily controlled, sample surface is not attacked, pumping systems are simplified and very good experimental reproducibility is obtained. 


\section{References}

[1] Thomas, P. A., Brodsky, M. H., KaPlan, D. and Lepine, D., Phys. Rev. B 18 (1978) 3059.

[2] Brodsky, M. H. and Titre, R. S., Phys. Rev. Lett. 23 (1969) 581.

[3] Thomas, P. A., Lepine, D. and Kaplan, D., in proceedings of the International Conference on Tetrahedrally Bonded Amorphous Semiconductors; Yorktown Heights, 1974 (AIP, New York 1974), p. 47.

[4] Kaplan, D., Sol, N. and Velasco, G., Thomas, P. A., Appl. Phys. Lett. 33 (5) (1978) 440.

[5] Spear, W. E. and Le Comber, P. G., in proceedings of the Seventh International Conference on Amorphous and Liquid Semiconductors Edinburgh 1977 (W. E. Spear Ed., Univ. of Edinburgh 1977) p. 309.

[6] Brodsky, M. H., Cardona, M. and Cuomo, J. J., Phys. Rev. B $16(1977) 3556$.
[7] Freeman, E. C. and Paul, W., Phys. Rev. B 18 (1978) 4288.

[8] Engemann, D. and Fischer, R., in Amorphous and Liquid Semiconductors, edited by J. Stuke and W. Brenig (London : Taylor and Francis) 1974 p. 947

[9] Street, R. A., Philos. Mag. B 37 (1978) 35.

[10] Thomas, P. A., Cernogora, J. and Mollot, F., to be published.

[11] Solomon, I., Dietl, T. and Kaplan, D., J. Physique 39 (1978) 1241.

[12] Taniellian, M., Fritzsche, H., Tsai, C. C. and Symbalisty, E., Appl. Phys. Lett. 33 (1978) 353.

[13] Ast, D. G. and Brodsky, M. H., to be published in Proc. of the 8th Int. Conf. on Amorphous and Liquid Semiconductors, Cambridge, August 1979. 